Bio - grafia. Escritos sobre la Biología y su Enseñanza. ISSN 2027

Edición Extraordinaria. p.p. 1289-1298

Memorias del VIII Encuentro Nacional de Experiencias en Enseñanza de la Biología y la Educación Ambiental. III Congreso Nacional de Investigación en Enseñanza de la Biología.

\title{
CATEGORÍAS CONCEPTUALES DE ESTUDIANTES DE GRADO OCTAVO SOBRE ETS LUEGO DE LA IMPLEMENTACIÓN DE UNA UNIDAD DIDÁCTICA DESDE EL ABP
}

\section{CONCEPTUAL CATEGORY IN EIGHTH GRADE STUDENTS ABOUT STD AFTER IMPLEMENTATION OF A DIDACTIC UNIT FROM THE PBL}

Páez Pérez Geraldine Yineth \& García Ariza Jeison Eduardo

\section{RESUMEN}

B

La OMS reporta que cada día más de un millón de personas adquieren una Infección de Transmisión Sexual; por lo anterior, el presente trabajo diseñó e implementó una unidad didáctica, bajo el enfoque $A B P$, con el fin de caracterizar las categorías conceptuales sobre ETS de los estudiantes de grado octavo que tenían edades que oscilaban de los 12 a los 16 años. El presente trabajo se sitúa desde el paradigma Interpretativo, analizando los escritos realizados por los estudiantes sobre las ETS luego del proceso de enseñanza. Los resultados evidencian que los escritos analizados de seis estudiantes, presentan alguna de las siguientes categorías: métodos anticonceptivos y de prevención de ETS, sintomatología, agente infeccioso, enunciación de ITS y ETS, sistemas del cuerpo afectados y causas de las ETS. Las frases escritas por los estudiantes expresan las preguntas sobre las ETS que a través de la implementación se abordaron; debido a que estas conducen a su pensamiento a encontrar una respuesta.

PALABRAS CLAVE: Categorías conceptuales, Enfermedades de Transmisión Sexual, Aprendizaje Basado en Problemas.

\section{ABSTRACT}

The OMS reports that every day more than a million people acquire a Sexually Transmitted Infection; so, this paper first designed and implemented a didactic unit under the PBL approach so to characterize the conceptual categories about STI of eighth grader students who had ages ranging from 12 to 16 years. This work is situated on the interpretive paradigm, analyzing the writings made by students about the STD. The results show that the writings analyzed of six students, have any of the following categories: contraception and STD prevention methods, symptoms, infectious agent, statement of STI and STD, body systems affected, and causes of STDs. Sentences written by students 
Bio - grafia. Escritos sobre la Biología y su Enseñanza. ISSN 2027

Edición Extraordinaria. p.p. 1289-1298

Memorias del VIII Encuentro Nacional de Experiencias en Enseñanza de la Biología y la Educación Ambiental. III Congreso Nacional de Investigación en Enseñanza de la Biología.

expressing questions about STD that they had across of the implementation of the didactic unit, because to that the questions lead his thinking to find an answer.

KEYWORDS: Conceptual categories, Sexually Transmitted Disease, Problem Based Learning.

\section{INTRODUCCIÓN}

La Organización Mundial de la Salud OMS reporta, en el informe de Noviembre de 2013, que cada día más de un millón de personas adquieren una Infección de Transmisión Sexual (ITS), estimando que anualmente 500 millones de personas contraen alguna de las cuatro ITS siguientes: clamidiasis, gonorrea, sífilis o tricomoniasis, reportando para la región de las Américas 126 millones de personas infectadas (OMS, 2014); adicionalmente, específicamente para el contexto colombiano, el ministerio de salud reporta para los años 2009 a 2011, un aumento de los casos de personas que presentan alguna ITS; lo cual, se ve reflejado en que para el año 2009 hubo un reporte de 8.043 personas; para el año 2010, 7.167 personas y para el año 2011, 10.773 personas infectadas, en un rango de edad de 15 a 19 años (Ministerio de Salud, 2014).

La OMS ha planteado dentro de sus pautas para la prevención de las ITS, que los procesos de enseñanza de esta temática resultan imprescindibles; sin embargo, se debe señalar que la historia de la enseñanza de las ciencias mostró que no todos los procesos de enseñanza conducían necesariamente a un aprendizaje, lo cual dio lugar a la formación de una nueva disciplina: la Didáctica (Gil, Carrascosa, \& Martínez, 2000); por lo anterior, los procesos de enseñanza deben caracterizarse por ser intencionados, es decir, deben definir qué enseñar, cómo enseñar, para qué enseñar, cuando enseñar y evaluar, entre otras preguntas, lo cual se puede alcanzar cuando el enseñante se ubica como docenteinvestigador. Esto le permite construir conocimientos mediante la sistematización de sus saberes, lo cual le permite transformar sus prácticas pedagógicas (Ceniceros, 2003). La unidad didáctica es una construcción hecha por el enseñante, la cual debe considerar todas las decisiones para responder dichas preguntas, en la que se determina cuáles serán los componentes del proceso de enseñanza (San Martín \& Sánchez, 2009). Sánchez \& Valcárcel (1993) plantean cinco componentes de la unidad didáctica: análisis científico de los contenidos; análisis didáctico de los contenidos; planteamiento de objetivos; selección de estrategias didácticas y selección estrategia de evaluación. 
Bio - grafia. Escritos sobre la Biología y su Enseñanza. ISSN 2027

Edición Extraordinaria. p.p. 1289-1298

Memorias del VIII Encuentro Nacional de Experiencias en Enseñanza de la Biología y la Educación Ambiental. III Congreso Nacional de Investigación en Enseñanza de la Biología.

El Aprendizaje Basado en Problemas ABP es una estrategia para enseñar y aprender, que busca que el estudiante comprenda y profundice adecuadamente en la respuesta a problemas cotidianos trabajando colaborativamente, con la ayuda de un profesor tutor (San Martín \& Sánchez, 2009). El ABP considera que los estudiantes son los máximos protagonistas, debido a que parte de las necesidades de aprendizaje de éstos; es decir, tiene en cuenta sus conocimientos y desconocimientos, hecho que es de gran importancia dado que tal como lo señala Giordan (1989), el aprendizaje de una noción o de una teoría científica depende de las representaciones del estudiante.

El ministerio de Educación por su parte, señala en los Estándares Básicos de Competencias en Ciencias Naturales, en la categoría "Ciencia, tecnología y sociedad", que los estudiantes al terminar grado octavo y noveno deben tener conocimientos que les permitan identificar y explicar medidas de prevención del embarazo y enfermedades de transmisión sexual (MEN, 2014).

El presente trabajo da a conocer las categorías conceptuales sobre ETS de seis estudiantes, luego de implementar la unidad didáctica denominada "Innova Tus caminos a la Sexualidad" desde el enfoque ABP, desarrollada en seis (6) sesiones de clase en el grado octavo, jornada tarde, con 27 estudiantes, de los que 15 eran mujeres y 12 hombres en el colegio Técnico Domingo Faustino Sarmiento IED, ubicado en la localidad de Barrios Unidos, Bogotá D.C. El trabajo se realizó en el marco de un proyecto semestral de la asignatura Aula Experimental y Recursos Educativos, de la Universidad Distrital Francisco José de Caldas.

\section{METODOLOGÍA}

El paradigma de investigación adoptado es de tipo Interpretativo, debido a que no se pretende alcanzar una generalización $y$, en lugar de buscar una causa se busca la comprensión del fenómeno (Beltran, 1995), reconociendo que el lenguaje juega un papel preponderante debido a que permite el entendimiento, y por ende una interpretación adecuada (Martínez, 2007).

El presente trabajo estuvo conformado por dos fases: la primera correspondió a la implementación de la unidad didáctica denominada "Innova Tus caminos a la Sexualidad", en 27 estudiantes de grado octavo del Colegio Técnico Domingo Faustino Sarmiento IED, ubicado en la localidad de Barrios Unidos, Bogotá D.C.; para lo cual, se caracterizó la institución, las prácticas del docente titular, y a los estudiantes y se diseñó e Implementó 
Bio - grafia. Escritos sobre la Biología y su Enseñanza. ISSN 2027

Edición Extraordinaria. p.p. 1289-1298

Memorias del VIII Encuentro Nacional de Experiencias en Enseñanza de la Biología y la Educación Ambiental. III Congreso Nacional de Investigación en Enseñanza de la Biología.

la Unidad Didáctica. Las enfermedades abordadas en la implementación de la unidad didáctica fueron: SIDA, Sífilis y Gonorrea, donde cada grupo de trabajo, se enfocó en alguna de ellas.

La segunda, correspondió a la caracterización de las categorías conceptuales de los estudiantes; para lo cual, se solicitó a éstos, al final del proceso, realizar un escrito sobre las ETS. Los análisis se realizan desde un marco teórico científico, debido a la ausencia de estudios didácticos relacionados con la enseñanza de las ITS y ETS. Los textos elaborados son analizados en seis estudiantes elegidos por su disposición desde las primeras actividades, planteando que dos (2) (Guillermo y Dayan) expresaban disposición para realizar las actividades, dos (2) desarrollaban las actividades pero no evidenciaban gran interés (David y Felipe) y dos (2) que no desarrollaban las actividades ni expresaban interés (Ricardo y Carmen). Las clases, para lo anterior, fueron registradas mediante grabaciones de audio y diarios de campo.

\section{RESULTADOS}

La primera categoría corresponde a los Métodos anticonceptivos y de prevención de ETS, ya que es una temática abordada por 5 de los 6 estudiantes, reconociendo en sus escritos frases como: "el condón es el único que nos ayuda a no contagiarnos de alguna enfermedad y evitar embarazos [...] es muy útil también para evitar infecciones" (Ricardo), "el condón ayuda a prevenir un embarazo no deseado y una enfermedad de transmisión sexual, las inyecciones y las pastillas son para prevenir un embarazo" (Dayan), "para prevenir alguna ETS debemos protegernos, el que nos protege [...] es el condón" (Carmen), "las enfermedades de transmisión sexual se pueden prevenir con el condón, pastillas y entre otros métodos" (David).

La segunda categoría hace alusión a la sintomatología, evidenciándose en tres de los seis estudiantes. En los escritos se encuentran frases, para cada caso enfermedad, como: "la enfermedad que tiene tres etapas, las cuales son: primera etapa, que la enfermedad empieza a manifestarse en el cuerpo, la segunda etapa produce granos, verrugas y erupciones cutáneas, en el cuello y la cara y la última etapa es mortal, produce cambios de trastornos mentales, ocurre cambios de personalidad" (David) correspondientes al caso clínico de la sífilis y "fiebres constantes, descamaciones, diarrea, sudoración, escalofríos y lo peor son las arrugas" (Guillermo), "inflamación de los ganglios del cuello, axilas e ingle. Otros sintomas son las descamaciones en la boca" (Felipe) para el caso del SIDA. 
Bio - grafia. Escritos sobre la Biología y su Enseñanza. ISSN 2027

Edición Extraordinaria. p.p. 1289-1298

Memorias del VIII Encuentro Nacional de Experiencias en Enseñanza de la Biología y la Educación Ambiental. III Congreso Nacional de Investigación en Enseñanza de la Biología.

La tercera categoría corresponde a la enunciación de ITS y ETS planteada por tres de los estudiantes en sus escritos, encontrándose afirmaciones como: "primero llega la infección y después se desarrolla la enfermedad" (Guillermo), "que gracias al ITS se puede desarrollar la ETS, lo cual es malo para una persona" (Dayan) y finalmente "que el ITS son bacterias [...] que infecta los órganos reproductores y se manifiesta después de entrar y el ETS son unos virus que atacan a la célula y los órganos del cuerpo humano" (David); adicionalmente hay un cuarto estudiante, pero éste sólo hace alusión a las ETS: "la enfermedad de transmisión sexual, que es el SIDA" (Felipe).

La cuarta categoría se refiere al Agente infeccioso de la enfermedad, siendo abordada sólo por 2 estudiantes, encontrando frases como: "son bacterias conocidas como Treponema pallidum que infecta los órganos reproductivos, que se manifiesta después de entrar estas bacterias" (David) en el caso de la sífilis y "el VIH o SIDA es un virus [...] el virus es el VIH en el caso que nos pasaron" (Guillermo) en el caso del SIDA.

La quinta categoría hace alusión a los sistemas del cuerpo que se ven afectados por la infección, reconociendo en los escritos de dos (2) estudiantes las siguientes afirmaciones: "el sida ataca al sistema inmunológico que es el que protege al cuerpo" (Felipe), "es un virus que ataca el sistema inmunitario, el cual es el virus del VIH en el caso que nos pasaron" (Guillermo).

La sexta categoría corresponde a la causa de las ETS, encontrándose frases como: "al no poder proteger el cuerpo varios virus invaden el cuerpo, uno de estos es el que hace que haiga descamaciones en la boca" (Felipe), "las enfermedades se pueden causar por el motivo de no usar protección" (Guillermo).

Las categorías conceptuales reconocidas son seis; adicionalmente, se identifica las categorías que cada uno de los estudiantes menciona en su escrito (ver Tabla 1).

Tabla 1. Categorías conceptuales de los estudiantes sobre las ETS.

\begin{tabular}{|l|l|l|l|}
\hline Número & Categorías & Descripción & $\begin{array}{l}\text { Mencionadas } \\
\text { por }\end{array}$ \\
\hline 1 & $\begin{array}{l}\text { Métodos } \\
\text { anticonceptivos y de } \\
\text { prevención de ETS }\end{array}$ & $\begin{array}{l}\text { El estudiante nombra los métodos } \\
\text { anticonceptivos y los métodos de } \\
\text { prevención de ETS. }\end{array}$ & $\begin{array}{l}\text { Dayan } \\
\text { Carmen } \\
\text { Ricardo }\end{array}$ \\
\hline 2 & Sintomatología & $\begin{array}{l}\text { El estudiante se enfoca en las } \\
\text { expresiones que a nivel morfológico tiene }\end{array}$ & $\begin{array}{l}\text { Guillermo } \\
\text { Felipe }\end{array}$ \\
\hline
\end{tabular}


Bio - grafia. Escritos sobre la Biología y su Enseñanza. ISSN 2027

Edición Extraordinaria. p.p. 1289-1298

Memorias del VIII Encuentro Nacional de Experiencias en Enseñanza de la Biología y la Educación Ambiental. III Congreso Nacional de Investigación en Enseñanza de la Biología.

\begin{tabular}{|c|c|c|c|}
\hline & & la infección. & David \\
\hline 3 & $\begin{array}{l}\text { Enunciación de ITS y } \\
\text { ETS. }\end{array}$ & $\begin{array}{l}\text { El estudiante nombra las ITS y ETS, } \\
\text { planteando una significación para cada una } \\
\text { de ellos. }\end{array}$ & $\begin{array}{l}\text { Guillermo } \\
\text { Felipe } \\
\text { David }\end{array}$ \\
\hline 4 & Agente infeccioso. & $\begin{array}{l}\text { El estudiante plantea un agente infeccioso } \\
\text { (virus o bacteria) para la enfermedad. }\end{array}$ & $\begin{array}{l}\text { Guillermo } \\
\text { David }\end{array}$ \\
\hline 5 & $\begin{array}{l}\text { Sistemas del cuerpo } \\
\text { que se ven afectados }\end{array}$ & $\begin{array}{l}\text { El estudiante se refiere a algún sistema } \\
\text { del cuerpo que se ve afectado por la } \\
\text { Infección de Transmisión Sexual. }\end{array}$ & Guillermo \\
\hline 6 & Causa de la ETS & $\begin{array}{l}\text { El estudiante plantea una decisión que } \\
\text { condujo a laETS. }\end{array}$ & $\begin{array}{l}\text { Guillermo } \\
\text { Felipe }\end{array}$ \\
\hline
\end{tabular}

\section{ANÁLISIS DE RESULTADOS}

El análisis se desarrolla para cada una de las seis categorías debido a que cuentan con características particulares. En la categoría correspondiente a los Métodos anticonceptivos y de prevención de ETS, se encuentran frases que permiten reconocer que algunos estudiantes como Ricardo y Dayan, consideran que el condón cumple una doble función: por un lado, ayuda a prevenir ETS; por otro lado, embarazos, lo cual coincide, con lo expresado por Ruíz, Plaa, Castro \& Solsona (2005), quienes afirman que el condón, además de su papel como anticonceptivo, ayuda a prevenir las enfermedades de transmisión sexual; sin embargo, el estudiante (David) confunde algunos métodos anticonceptivos con métodos de prevención de ETS, hecho que se evidencia desde el proceso de caracterización, y perdura a pesar de que en las diferentes sesiones, se hizo la distinción por medio de videos, clases magistrales entre otros. David considera que las pastillas anticonceptivas, al igual que el condón, sirven para prevenir las ETS; sin embargo, SET (2006) expresa que las cremas vaginales espermicidas, el diafragma y otros métodos anticonceptivos no sirven para prevenir ETS.

La segunda categoría corresponde a la sintomatología de los casos clínicos, encontrándose que los estudiantes que trabajaron con la gonorrea no la expresaron. Los sintomas de la sífilis, cuentan con tres (3) etapas (sífilis precoz, sífilis secundaria y sífilis terciaria) según lo reporta Romero (2007), lo cual, es expresado por el estudiante (David). Elizondo (2002) afirma que cada etapa se caracteriza por expresar diferentes síntomas, debido a que es una enfermedad sistémica progresiva que de no ser tratada produce 
Bio - grafia. Escritos sobre la Biología y su Enseñanza. ISSN 2027

Edición Extraordinaria. p.p. 1289-1298

Memorias del VIII Encuentro Nacional de Experiencias en Enseñanza de la Biología y la Educación Ambiental. III Congreso Nacional de Investigación en Enseñanza de la Biología.

deterioro final del sistema nervioso central y del aparato cardiovascular, lo cual, es expresado parcialmente por David, porque él a pesar de que habla de la locura, trastornos mentales, entre otros, no los asocia al deterioro del sistema nervioso central, y tampoco habla del aparato cardiovascular; por otro lado, en la sintomatología del SIDA, Guillermo expresa los sintomas primarios, que se presentan en las primeras semanas, coincidiendo en algunos de éstos con Carrasco (2004), como lo son: fiebre, sudoración y diarrea. Mientras que (Felipe) se centra en los síntomas de respuesta inmunitaria, como lo es la inflamación de los ganglios linfáticos, pero sin explicar que se debe a la replicación activa del virus (Carrasco, 2004).

La tercera categoría corresponde a la enunciación de los términos ITS y ETS, aspecto que se trabajó desde las primeras sesiones, en donde Tortora (2007) dice que una infección es cuando el patógeno penetra e invade al cuerpo humano y posteriormente tras llevar a cabo parte de su ciclo vital, dentro del huésped, produce la enfermedad. Una aproximación cercana se puede evidenciar en los escritos de Guillermo y Dayan, pero no en el escrito de David en el que se evidencia una confusión al relacionar las ITS con las bacterias y las ETS con los virus, atribuyéndole alguna de estas categorías (ITS-ETS) a los organismos causales y no al proceso en el cuerpo.

La cuarta categoría hace alusión al agente infeccioso de la sífilis y el SIDA específicamente. El agente causal de la sífilis según Carmona (2005), es una bacteria de tipo espiroqueta denominada Treponema pallidum; lo anterior, coincide con la respuesta dada por David; adicionalmente, habla de la expresión corporal, pero no explica que se debe al ciclo vital del microorganismo (Tortora, 2007). El SIDA según Tamames (1997), es la manifestación clínica de la infección por el Virus de la Inmunodeficiencia Humana; lo cual, coincide parcialmente con la respuesta de Guillermo, en tanto considera que el VIH es un virus; pero, sitúa al SIDA y al VIH como sinónimos, aspecto que permite reconocer que no identifica al VIH como agente etiológico del SIDA y por ende no logra comprender el ciclo de replicación de los virus, y tampoco diferenciar las ITS de ETS.

La quinta categoría corresponde a los sistemas del cuerpo que se ven afectados tras la infección; los cuales sólo fueron mencionados por los estudiantes que trabajaron con el SIDA. El VIH según Chicharro \& López (2008) destruye a los linfocitos CD4, que integran el sistema inmunológico; para ello, reconoce a las células diana mediante su cubierta de glucoproteínas transmembrana gp4 y las glucoproteínas de cubierta gp120. Los estudiantes Felipe y Guillermo no mencionan lo anterior, pero se refieren a la afección que 
Bio - grafia. Escritos sobre la Biología y su Enseñanza. ISSN 2027

Edición Extraordinaria. p.p. 1289-1298

Memorias del VIII Encuentro Nacional de Experiencias en Enseñanza de la Biología y la Educación Ambiental. III Congreso Nacional de Investigación en Enseñanza de la Biología.

sufre el sistema inmunológico; pero, debe resaltarse que no se evidencia una explicación por parte de ellos, en torno a cómo el VIH ataca a dicho sistema, y por qué no ataca de igual forma a otro, hecho que permite interpretar que el estudiante no presenta claridad conceptual de los procesos de reconocimiento de células diana y replicación del virus y la correspondiente afección de las células CD4.

La sexta categoría corresponde a la causa de las ETS. Felipe y Guillermo atribuyen las descamaciones de la boca, y la presencia de la enfermedad al hecho de no proteger el cuerpo contra los virus; permitiendo reconocer, que considera como responsable de esta sintomatología el acto de no usar condón; lo cual, coincide con Campos (2002), quien recomienda el uso de preservativos. Los estudiantes en este punto no mencionan las vías de transmisión sanguínea.

\section{CONCLUSIONES}

Los estudiantes expresan en sus escritos seis categorías conceptuales en torno a las ETS: métodos de prevención y anticonceptivos, sintomatología, agente infeccioso, enunciación de ITS y ETS, sistemas afectados y causas de la enfermedad. La categoría más nombrada por los estudiantes fue métodos de prevención de las ETS, apareciendo el condón como un elemento que puede usarse con dos fines: prevenir ITS y embarazos. La segunda categoría más nombrada corresponde a la sintomatología, reconociendo que algunos estudiantes describen las enfermedades de forma similar a la presentada por los docentes investigadores en las clases.

Las categorías conceptuales permiten afirmar que se requieren determinados conceptos, para una comprensión mayor de las ETS, como los son: célula, bacteria, ADN y ARN, entre otros; debido a que, por ejemplo, la categoría de enunciación de ITS y ETS parte de la comprensión de los procesos de replicación del virus o de reproducción de las bacterias.

Las preguntas abordadas por cada uno de los seis estudiantes en el trascurso de las sesiones de clase se evidencian en las categorías de los escritos; lo cual, permite reconocer que cada sujeto cuenta con preguntas particulares, las cuales contarán con una respuesta de igual propiedad. 
Bio - grafia. Escritos sobre la Biología y su Enseñanza. ISSN 2027

Edición Extraordinaria. p.p. 1289-1298

Memorias del VIII Encuentro Nacional de Experiencias en Enseñanza de la Biología y la Educación Ambiental. III Congreso Nacional de Investigación en Enseñanza de la Biología.

\section{BIBLIOGRAFÍA}

Beltran, J. (1995). Psicología en la Educación. Barcelona: Marcombo S.A.

Campos, P. (2002). Biología 2. Mexico: Limusa.

Carmona, J. (2005). Enfermedad y sociedad en los primeros tiempos modernos. España: Universidad de Sevilla.

Carrasco, L. (2004). El virus del SIDA: un desafío pendiente. Madrid: Hélice.

Cenicero, D. (2003). El profesor como investigador: una perspectiva critica. Investigación Educativa Duranguense (págs. 4-10).

Chicharro, J., \& López, L. (2008). Fisiología clínica del ejercicio. Madrid: Ed. Médica Panamericana.

Elizondo, L. (2002). Principios básicos de salud. Vol 2. Mexico D.F.: Limusa.

Gil, D., Carrascosa, J., \& Martínez, F. (2000). Una disciplina emergente y un campo específico de investigación. En P. Cañal de León, Didáctica de las ciencias experimentales: teoría y práctica de la enseñanza de las ciencias (págs. 11-34). España: Marfil.

Giordan, A. (1988). Conceptos de biología. Madrid: Labor S.A.

Martínez, R. (2007). La investigación en la práctica educativa: guía metodológica de investigación para el diagnóstico y evaluación en los centros docentes. Madrid: Ministerio de educación y ciencia.

MEN. (18 de Noviembre de 2014). Todos por un nuevo país. Obtenido de http://www.mineducacion.gov.co/1621/articles-116042_archivo_pdf3.pdf

Ministerio de Salud. (18 de Noviembre de 2014). Todos por un nuevo país. Obtenido de 
Bio - grafia. Escritos sobre la Biología y su Enseñanza. ISSN 2027

Edición Extraordinaria. p.p. 1289-1298

Memorias del VIII Encuentro Nacional de Experiencias en Enseñanza de la Biología y la Educación Ambiental. III Congreso Nacional de Investigación en Enseñanza de la Biología.

http://www.minsalud.gov.co/salud/Documents/observatorio_vih/documentos/monitoreo_ev aluacion/1_vigilancia_salud_publica/a_situacion_epidimiologica/SITUACION\%20DE\%2OLA S\%2OINFECCIONES\%20DE\%20TRANSMISION1.pdf

OMS. (18 de Noviembre de 2014). Centro de prensa. Obtenido de Infecciones de Transmisión Sexual: http://www.who.int/mediacentre/factsheets/fs110/es/

Romero, R. (2007). Microbiologia y parasitologia humana / Microbiology and Human Parasitology: Bases etiologicas de las enfermedades infecciosas y parasitarias. Mexico: Medica Panamerica.

Ruíz, M., Plaa, A., Castro, T., \& Solsona, M. (2005). Anticoncepción y salud reproductiva en España: crónica de una ( $r$ )ecolución. España: CSIC.

San Martín, E., \& Sánchez, I. (2009). Unidad didáctica para abordar el concepto de célula desde la resolución de problema por investigación. Paradígma, 63-68.

Sanchez, G., \& Valcárcel, M. (1993). Diseño de unidades didácticas en el área de ciencias experimentales. Enseñanza de las ciencias, 33-44.

SET. (2006). Tratado SET de trastornos adictivos. España: Ed. Médica Panamericana.

Tamames, S. (1997). Cirugía. Madrid: Médica Panamerica.

Tortora, G., Funke, B., \& Case, C. (2007). Introducción a la microbiología. Buenos Aires: Ed. Medica Panamericana.

Zambrano, M., \& Díaz, J. (2014). Construcción del CDC del concepto de Biodiversidad de los profesores en formación en Biología a través de la Interpretación del diseño e implementación de la Unidad Didáctica. Bogotá D.C.: Universidad Distrital F.J.C. 